\title{
PEMANFAATAN LIMBAH CANGKANG TELUR AYAM SEBAGAI ADSORBEN PADA PEMURNIAN GLISEROL DENGAN METODE ASIDIFIKASI DAN ADSORPSI
}

\author{
UTILIZATION OF CHICKEN EGG WASTE AS ADSORBEN ON GLYCEROL \\ PURIFICATION USING ACIDIFICATION AND ADSORPTION METHODS
}

\author{
Sandro Nadeak*, Jesica Mentari Hasibuan, Lies Widya Naibaho, Mersi Suriani Sinaga \\ Departemen Teknik Kimia, Fakultas Teknik, Universitas Sumatera \\ Utara, Jl. Almamater Kampus USU, Medan 20155, Indonesia \\ *Email: sandronadeak42@gmail.com
}

\begin{abstract}
Abstrak
Gliserol sebagai hasil samping produksi biodiesel rata-rata terbentuk 10-20\% dari berat biodiesel. Pengotor yang terkandung dalam crude gliserol seperti garam anorganik, katalis, air serta matter organic non glycerol (MONG) yang mengandung asam lemak bebas, asam lemak sisa metil ester, gliserida, dan alkohol (umumnya metanol atau etanol) memberikan pengaruh signifikan pada konsentrasi gliserol. Untuk itu diperlukan beberapa perlakuan terutama untuk menghilangkan impuritisnya. Penelitian ini bertujuan untuk memurnikan gliserol dengan metode asidfikasi menggunakan fosfat dan adsorpsi dengan limbah cangkang telur ayam. Percobaan diawali dengan pretreatment gliserol dengan asam fosfat dengan variabel uji rasio berat (w/w) asam yang ditambahkan $(1: 0,2 ; 1: 0,4 ; 1: 0,6 ; 1: 0,8$ dan 1:1), dilanjutkan dengan adsorpsi menggunakan limbah cangkang telur ayam yang sudah diaktivasi secara termal dengan variabel uji persen berat adsorben (\%w/w) 3\%, 6\%, 9\%, 12\% dan 15\% dengan kondisi reaksi kecepatan pengadukan 250 rpm dan waktu adsorpsi 120 menit. Hasil kemurnian terbaik didapatkan pada rasio berat (w/w) asidifikasi 1:0,6, persen berat adsorben (\%w/w) 15\% dengan kadar gliserol sebesar 67,22\%, densitas $1,171 \mathrm{~g} / \mathrm{cm}^{3}$, kadar air 2,796\%, kadar abu 13,852\% dan kadar MONG 16,130\%.
\end{abstract}

Kata kunci: crude gliserol, MONG, asidifkasi, adsorpsi.

\begin{abstract}
Glycerol as a byproduct of biodiesel production was approximately formed 10-20\% of the biodiesel weight. Impurities which contained in the glycerol such as inorganic salts, catalysts, water and matter organic non glycerol (MONG) which contained free fatty acids, fatty acids as residual of methyl ester, glycerides, and alcohols (generally methanol or ethanol) had a significant effect on glycerol concentration. We needed some treatment, especially to eliminate the impuritis. This study aims to purify glycerol by acidfication using phosphate and adsorption with chicken egg shell waste. This research was begun with the pretreatment of glycerol using phosphoric acid with the variable of test weight ratio $(w / w)$ acid added $1: 0.2 ; 1: 0.4 ; 1: 0.6 ; 1: 0.8$ and $1: 1$, continued with adsorption using thermally activated chicken egg shell waste with the variable weight percent adsorbent $(\% w / w) 3 \%$, $6 \%, 9 \%, 12 \%$ and $15 \%$ with reaction conditions, stirring speed $250 \mathrm{rpm}$ and adsorption time 120 minutes. The purest result was obtained at weight ratio $(w / w)$ acidification of $1: 0.6$, weight percent adsorbent (\% w/w) 15\% with glycerol content of $67.22 \%$, density $1.171 \mathrm{~g} / \mathrm{cm} 3$, moisture content $2.796 \%$, ash content $13.852 \%$ and MONG content $16.130 \%$.
\end{abstract}

Key words: crude glycerol, $M O N G$, acidification, adsorption. 


\section{Pendahuluan}

Pada pembuatan biodiesel atau reaksi transesterifikasi minyak atau lemak dihasilkan produk samping berupa gliserol dengan tingkat kemurnian yang rendah yang biasa disebut dengan crude gliserol. Produk ini dihasilkan 10$20 \%$ dari total volume produk [5]. Asosiasi produsen biofuel Indonesia mencatat produksi biodiesel januari-juni 2018 mencapai 3 miliar liter dengan distribusi 1,64 miliar liter. Dengan jumlah biodiesel sebesar itu akan dihasilkan crude gliserol sekitar 3 ratus juta liter pertahunnya [11]. Selama ini crude gliserol yang dihasilkan belum dimanfaatkan oleh industri penghasil biodiesel karena banyaknya zat pengotor yang terdapat dalam crude gliserol. Pengotor dalam crude gliserol ini biasanya mengandung gliserol, garam anorganik, katalis, air serta matter organic non glycerol (MONG) yang mengandung asam lemak bebas, asam lemak sisa metil ester, gliserida, dan alkohol (umumnya metanol atau etanol). Jika crude gliserol tadi dimurnikan akan memiliki kegunaan yang sangat banyak seperti sebagai bahan baku industri makanan, farmasi, produk kimia ataupun kosmetik dan sebagai bahan bakar aditif [7]. Oleh sebab itu pemurnian crude gliserol perlu dilakukan, selain dapat mengurangi limbah yang dihasilkan dari proses pembuatan biodiesel, juga akan menambah pendapatan bagi industri biodiesel, karena selain produk utama biodiesel masih ada produk samping yang bernilai ekonomis. Pemurnian crude gliserol dapat dilakukan dengan destilasi, pertukaran ion, dan pemurnian dengan fisikokimia seperti filtrasi, saponifikasi, asidifikasi, netralisasi, ekstraksi dan adsorpsi [4].

Aziz (2014) melaporkan bahwa pemurnian gliserol dengan menggunakan asam sulfat dan adsorpsi dengan zeolit dapat meningkatkan kemurnian gliserol dari $60,74 \%$ menjadi $88,91 \%$ [3]. Lestari (2015) melaporkan bahwa konsentrasi asam fosfat $5 \%$ dan berat semen putih 5 gram pada pemurnian crude gliserol diperoleh kadar kemurnian tertinggi yaitu $84,20 \%$ [12]. Sedangkan Windi (2016) menggunakan asam klorida untuk proses asidifikasi, dilanjutkan dengan proses ekstraksi dengan kloroform dan adsorpsi dengan karbon aktif dapat meningkatkan kemurnian gliserol dari $74,716 \%$ menjadi 90,90\% [24]. Perbedaan proses yang digunakan, penggunaan asam dalam proses asidifikasi dan penggunaan adsorben ternyata mempengaruhi kemurnian gliserol yang diperoleh.

Cangkang telur merupakan bagian terluar dari telur yang berfungsi memberikan perlindungan bagi komponen-komponen isi telur dari kerusakan secara fisik, kimia maupun mikrobiologis. Berdasarkan komposisi mineral yang ada, maka cangkang telur tersusun atas kristal $\mathrm{CaCO}_{3}(98,41 \%), \mathrm{MgCO}_{3}(0,84 \%)$ dan $\mathrm{Ca}_{3}(\mathrm{PO} 4)_{2}(0,75 \%)$ [9]. Cangkang telur memiliki kadar kalsium yang cukup tinggi sehingga memiliki potensi untuk menjadi penyerap atau adsorben. Biosorben yang berasal dari limbah cangkang telur dapat digunakan untuk pengolahan limbah hasil industri, yaitu limbah logam berat [14].

Dalam penelitian ini, beberapa proses diatas dikombinasikan yaitu dengan menggunakan perlakuan asidifikasi dengan asam fosfat sebagai pretreatment awal kemudian dilanjutkan dengan adsorpsi dimana adsorben yang digunakan adalah limbah cangkang telur ayam yang diharapkan akan didapat gliserol dengan kemurnian yang tinggi dan juga warna yang bersih.

\section{Teori}

Gliserol adalah zat tidak berwarna, tidak berbau, kental cair dengan rasa manis, yang berasal dari alam dan biasanya terdapat sebagai trigliserida yang bercampur dengan bermacammacam asam lemak seperti asam stearat, asam palmitat, asam laurat, dan sebagian lemak [21]. Gliserol diperoleh sebagai produk samping dari empat proses yaitu transesterifikasi (produksi biodiesel), safonifikasi (produksi sabun), hidrolisis untuk produksi asam lemak dan mikrobial [13].

Untuk produksi biodiesel setiap ton di peroleh $100 \mathrm{~kg}$ crude gliserol. Crude gliserol merupakan cairan yang sangat kental dengan warna coklat gelap dan memiliki pH 9,6 [18]. Crude gliserol mengandung impuritis seperti garam anorganik, MONG dan air. MONG terdiri dari FAME (Fatty Acid Methyl Ester), tri, di dan mono gliserida, beberapa jenis asam lemak bebas dan metanol atau etanol [6]. Pada umumnya komposisi dari crude gliserol tergantung pada bahan baku dan proses yang digunakan dalam memproduksi biodiesel [23]. Oleh karena itu, pemurnian gliserol diperlukan untuk menghilangkan semua pengotor tersebut [17]. Cara umum yang digunakan untuk meningkatkan kemurnian gliserol diantaranya adalah dengan distilasi, filtrasi, perlakuan kimia, adsorpsi (dengan activated carbon), resin penukar ion, ekstraksi, filtrasi, dekantasi dan kristalisasi, dimana berbagai metode yang digunakan tergantung pada karakteristik gliserol yang akan dimurnikan [22].

Sebagai pretreatment awal, dilakukan asidifikasi yaitu dengan penambahan asam pada bahan baku gliserol. Gliserol ditambahkan asam 
untuk menetralkan katalis basa yang digunakan dan memecah sabun yang terbentuk menjadi asam lemak bebas dan garam . Garam-garam ini memiliki kelarutan yang sangat sedikit dalam gliserol, maka garam-garam yang terbentuk ini nantinya akan mengendap di bagian dasar [6]. Reaksi netralisasi dengan penambahan asam ini merupakan reaksi eksoterm dimana reaksi mengeluarkan panas sehingga penambahan asam harus dilakukan secara perlahan dan juga dengan pengadukan agar panas yang dihasilkan tidak terjadi secara mendadak [24].

Saat asam ditambahkan ke dalam gliserol, maka akan terbentuk dua atau tiga lapisan, dimana pada lapisan atas merupakan lapisan yang mengandung asam lemak bebas, lapisan tengah adalah lapisan yang kaya akan gliserol, dan lapisan bawah merupakan garam-garam anorganik, katalis yang mengendap. Asam yang digunakan untuk proses asidifikasi adalah asam fosfat $\left(\mathrm{H}_{3} \mathrm{PO}_{4}\right)$, karena asam fosfat tidak berbahaya untuk lingkungan dan produk yang dihasilkan berupa tripotasium phosphate penggunaannya sangat luas sebagai pupuk [8]. Untuk meningkatkan kemurnian gliserol dan menurunkan kandungan air dan MONG. Penggunaan adsorben diperlukan untuk mengeliminasi pengotor seperti asam lemak bebas, metil ester, air dan kalium [19]. Adsorben yang digunakan adalah cangkang telur ayam. Cangkang telur ayam tersusun atas kristal $\mathrm{CaCO}_{3}$ $(98,41 \%), \quad \mathrm{MgCO}_{3} \quad(0,84 \%)$ dan $\mathrm{Ca}_{3}\left(\mathrm{PO}_{4}\right)_{2}$ $(0,75 \%)$. Setiap cangkang telur memiliki 10.000 20.000 pori-pori sehingga diperkirakan dapat menyerap suatu solute dan dapat digunakan sebagai adsorben. Disamping itu kandungan terbesar cangkang telur adalah kalsium karbonat, dimana kalsium karbonat ini termasuk ke dalam adsorben polar [9].

\section{Metodologi Penelitian \\ Bahan Baku dan Peralatan Penelitian}

Bahan-bahan yang digunakan dalam penelitian ini adalah crude gliserol hasil samping pembuatan biodiesel dengan kemurnian $37,2283 \%$, asam fosfat $\left(\mathrm{H}_{3} \mathrm{PO}_{4}\right)$, natrium hidroksida $(\mathrm{NaOH})$ (p.a) $12,5 \mathrm{M}$, aquadest $\left(\mathrm{H}_{2} \mathrm{O}\right)$, limbah cangkang telur ayam, asam sulfat $\left(\mathrm{H}_{2} \mathrm{SO}_{4}\right)$ $0,2 \mathrm{~N}$, sodium periodate $\left(\mathrm{NaIO}_{4}\right)$, etilen glikol dan indikator biru bromtimol. Peralatan yang digunakan dalam penelitian ini adalah erlenmeyer, magnetic stirrer, hot plate, corong pemisah, beaker glass, gelas ukur, neraca digital, batang pengaduk, termometer, corong gelas, pipet tetes, stopwatch, $\mathrm{pH}$ meter.

\section{Prosedur Penelitian \\ Pretreatment Bahan Baku}

Sebagai langkah pretreatment, dimasukkan gliserol dengan berat 30 gram ke dalam erlenmeyer, kemudian ditambahkan asam fosfat dengan rasio yang telah ditentukan. Campuran dipanaskan hingga mencapai suhu $70^{\circ} \mathrm{C}$ dan dilakukan pengadukan dengan kecepatan 250 rpm selama 1 jam, kemudian dimasukkan ke dalam corong pemisah dan didiamkan hingga terbentuk tiga lapisan. Dilfiltrasi untuk menghilangkan garam yang mengendap. Lapisan gliserol diambil dan dilakukan penetralan dengan $\mathrm{NaOH}$. Setelah itu gliserol dievaporasi untuk menghilangkan kadar air.

\section{Pembuatan Adsorben Cangkang Telur Ayam}

Limbah cangkang telur ayam dicuci dengan air keran hingga bersih dan lapisan membran dilepas dan dipisahkan dari cangkangnya kemudian limbah cangkang telur ayam dikeringkan dan dihancurkan menjadi lebih kecil dengan lumpang dan alu serta digiling menjadi serbuk dengan ball mill. Selanjutnya serbuk cangkang telur ayam diayak dengan ayakan yang berukuran 100 mesh, hasil ayakan yang lolos di furnace selama 2 jam dengan suhu $600^{\circ} \mathrm{C}$. Setelah itu hasil pemanasan disimpan dalam desikator selama 24 jam.

\section{Proses adsorpsi}

Limbah cangkang telur ayam dan gliserol dimasukkan dengan persen berat yang telah ditentukan, kemudian dicampur dengan pengadukan 250 rpm selama 2 jam dan dilakukan filtrasi.

\section{Analisis Produk}

Analisis terhadap gliserol yang telah dimurnikan yang dihasilkan meliputi analisis komposisi bahan baku dan produk dengan kromatograf gas, kadar air, kadar abu, kadar MONG (Matter Organic Non Glycerol), pH, dan kadar gliserol.

\section{Hasil}

Karakteristik Crude Gliserol

Tabel 1 adalah sifat fisika dari crude gliserol dan sifat fisika gliserol standard BS 2621 : 1979.

\section{Tabel 1. Sifat Fisika Crude Gliserol}

\begin{tabular}{|l|c|l|}
\hline Sifat Fisika & $\begin{array}{l}\text { Crude } \\
\text { Gliserol }\end{array}$ & $\begin{array}{l}\text { Glierol } \\
\text { Standard BS } \\
\mathbf{2 6 2 1}: \mathbf{1 9 7 9}[\mathbf{1 ]}\end{array}$ \\
\hline Gliserol (\%) & 37,2283 & $>80$ \\
\hline Metil Ester $(\%)$ & 55,9646 & - \\
\hline Densitas (g/cm $\left.{ }^{3}\right)$ & 1,134 & 1,2671 \\
\hline Kadar Abu (\%) & 22,799 & $<10$ \\
\hline Kadar Air $(\%)$ & 6,736 & $<10$ \\
\hline MONG (\%) & 33,236 & $<2.5$ \\
\hline
\end{tabular}




\section{Asidifikasi Asam Fosfat}

Asidifikasi dilakukan sebagai tahap pretreatment crude gliserol. Saat asam ditambahkan ke dalam gliserol, maka akan terbentuk dua atau tiga lapisan, dimana pada lapisan atas merupakan lapisan yang mengandung asam lemak bebas, lapisan tengah adalah lapisan yang kaya akan gliserol, dan lapisan bawah merupakan garam-garam anorganik atau katalis yang mengendap [8]. Lapisan gliserol yang terbentuk setelah proses asidifikasi dapat dilihat pada gambar 1 .

Penambahan asam menyebabkan terjadinya reaksi netralisasi basa dan juga pemecahan sabun [24]. Dalam kondsi asam yang kuat, asam menetralisasi hampir semua basa yang terdapat dalam crude gliserol yang kemudian akan mengendap menjadi padatan di bagian bawah, dan bereaksi dengan sabun membentuk asam lemak yang akan berada pada bagian atas gliserol [16]. Reaksi penguraian sabun menjadi asam lemak dapat dilihat pada reaksi berikut:

\section{$\mathrm{R}-\mathrm{COOK}+\mathrm{H}_{3} \mathrm{PO}_{4} \longrightarrow \mathrm{R}-\mathrm{COOH}+\mathrm{KH}_{2} \mathrm{PO}_{4}$ Sabun A.Fosfat A.Lemak Garam}

Berdasarkan reaksi diatas, sabun yang direaksikan dengan asam (asidifikasi) akan terpecah kembali menjadi asam-asam lemaknya dan akan menghasilkan garam kalium fosfat. Kelebihan asam pada proses asidifikasi kemudian di netralisasi dengan menggunakan basa, karena pada proses asidifikasi digunakan asam kuat maka basa yang digunakan juga basa kuat [6].

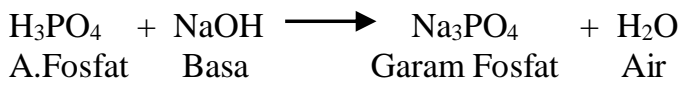

Dari reaksi diatas dihasilkan endapan garam fosfat dan air. Tahap selanjutnya adalah pemanasan. Pemanasan ini dilakukan untuk mempercepat terbentuknya garam dan juga untuk penguapan air yang terbentuk dari hasil reaksi. Setelah pemanasan, maka kemudian dilakukan filtrasi untuk menyaring garam-garam yang mengendap. Filtrasi dilakukan denga kertas Whatman No.1.

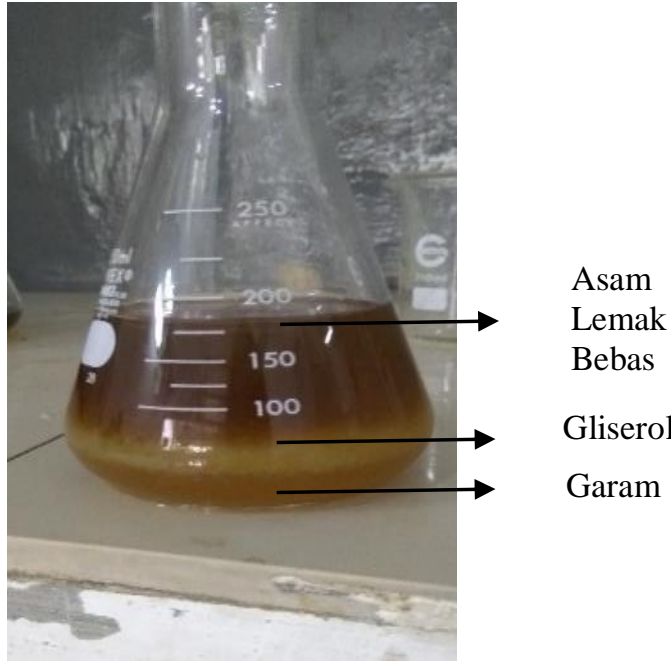

Gambar 1. Lapisan Gliserol yang Terbentuk Setelah Proses Asidifikasi

\section{Adsorpsi dengan Limbah Cangkang Telur Ayam}

Tahap selanjutnya setelah asidifikasi adalah adsorpsi dengan menggunakan cangkang telur ayam yang sudah diaktifasi secara termal pada suhu $600{ }^{\circ} \mathrm{C}$ selama 2 jam dengan kondisi reaksi pengadukan $250 \mathrm{rpm}$ dan waktu 120 menit.

Proses aktivasi fisika adalah suatu perlakuan termal terhadap adsorben yang bertujuan untuk memperbesar pori yaitu dengan cara memecahkan ikatan kimia atau mengoksidasi molekul permukaan sehingga luas permukaan bertambah besar dan berpengaruh terhadap daya adsorpsi. Luas permukaan adsorben merupakan salah satu karakter fisik yang memiliki peranan penting dimana berhubungan langsung dengan kemampuan adsorpsi adsorben terhadap zat-zat yang dijerap, karena banyaknya zat yang dapat teradsorpsi selain tergantung pada situs aktif ditentukan juga oleh luas permukaannya. Semakin luas permukaan adsorben, maka memberikan bidang kontak yang lebih besar sehingga semakin banyak adsorbat yang dijerap dan proses adsorpsi semakin efektif.

Jasinda pada tahun 2013 dalam penelitiannya melaporkan bahwa aktifasi termal cangkang telur ayam pada suhu $600{ }^{\circ} \mathrm{C}$ selama 2 jam menghasilkan luas permukaan adsorben $2700,978 \mathrm{~m}^{2} / \mathrm{g}$ dan sudah sesuai dengan standard luas permukaan adsorben komersial yang ada dimana standar luas permukaan alumina aktif $320 \mathrm{~m}^{2} / \mathrm{g}$; silika gel $750-850 \mathrm{~m}^{2} / \mathrm{g}$; karbon aktif $400-1.200 \mathrm{~m}^{2} / \mathrm{g}$; karbon molecular sieve $400 \mathrm{~m}^{2} / \mathrm{g}$; dan zeolit $600-700 \mathrm{~m}^{2} / \mathrm{g}$ [10]. Setelah didapatkan gliserol yang sudah murni, maka dilakukan berbagai analisa seperti analisa densitas, kadar 
air, kadar abu, MONG, pH dan juga kadar gliserol.

\section{Pengaruh Asidifkasi Terhadap Kemurnian Gliserol.}

Tabel 2 adalah sifat fisika crude gliserol dan gliserol hasil asidifikasi pada rasio berat gliserol : asam fosfat 1:0,6.

Tabel 2. Sifat Fisika Crude Gliserol dan Gliserol Hasil Asidifikasi Pada Rasio Berat Gliserol: Asam Fosfat 1:0,6.

\begin{tabular}{|l|l|l|}
\hline Sifat Fisika & $\begin{array}{l}\text { Crude } \\
\text { Gliserol }\end{array}$ & $\begin{array}{l}\text { Gliserol Hasil } \\
\text { Asidifikasi }\end{array}$ \\
\hline Kadar Gliserol (\%) & 37,228 & 58,135 \\
\hline Densitas (g/cm $\left.{ }^{3}\right)$ & 1,1134 & 1,156 \\
\hline Kadar abu (\%) & 22,799 & 16,096 \\
\hline Kadar air (\%) & 6,736 & 3,784 \\
\hline MONG (\%) & 33,236 & 21,985 \\
\hline pH & 10 & 3 \\
\hline Warna & $\begin{array}{l}\text { Coklat } \\
\text { Gelap }\end{array}$ & Kuning \\
& \multicolumn{2}{|l}{} \\
\hline
\end{tabular}

Pada tabel 2 dapat dilihat bahwa setelah proses asidifikasi kadar gliserol meningkat dari 37,2283 menjadi $58,1358 \%$. Kadar asam yang semakin tinggi, akan mengakibatkan proses asidifikasi emulsi menjadi asam lemak akan semakin tinggi, sehingga kadar kemurnian gliserol pun akan semakin baik. Namun, dapat juga terjadi asdifikasi berlebih. Dimana proses asidifikasi tidak berjalam maksimal sehingga sabun pada crude gliserol tidak terurai yang mengakibatkan gliserol tidak dapat dipisahkan dari garam dan asam lemaknya [12]. Dimana akan terjadi stratum antara asam lemak dan lapisan gliserol yang mengandung garam, sehingga garam menjadi tidak bisa lagi mengendap. Selain kosentrasi asam, $\mathrm{pH}$ juga mempengaruhi kadar gliserol yang diperoleh dimana pada $\mathrm{pH} 3$ kadar gliserol akan menunjukkan hasil yang optimum, pada $\mathrm{pH} 2$ terjadi asidifikasi yang berlebih dan pada $\mathrm{pH} 4$ terjadi asidifikasi yang tidak sempurna [20].

Pada tabel 2 dapat juga dilihat bahwa setelah proses asidifikasi kadar air, kadar abu mengalami penurunan sedangkan densitas mengalami peningkatan. Kadar abu mengalami penurunan dari $22,799 \%$ menjadi $16,096 \%$, kadar air mengalami penurunan dari 6,376 menjadi $3,784 \%$ dan densitas meningkat dari $1,1134 \mathrm{gr} / \mathrm{cm}^{3}$ menjadi $1,156 \mathrm{gr} / \mathrm{cm}^{3}$. Kadar air merupakan banyaknya air yang terkandung dalam bahan yang dinyatakan dalam persen. Penurunan kadar air disebabkan reaksi dehidrasi gliserol selama proses pengasaman. Kadar abu menunjukkan kandungan materi anorganik seperti garam kalium, yang berasal dari katalis yang digunakan pada proses transesterifikasi. Kandungan garam ini dipengaruhi oleh $\mathrm{pH}$ dari perlakuan kimia yang dilakukan pada crude gliserol. Semakin tinggi $\mathrm{pH}$ larutan maka semakin meningkat pula kelarutan garam katalis dalam crude gliserol yang menyebabkan tingginya kadar abu [3]. semakin rendah $\mathrm{pH}$ maka semakin baik proses penguraian sabun menjadi asam lemak sehingga sisa-sisa logam pun akan lebih rendah yang mengakibatkan kadar abu rendah. Densitas dipengaruhi oleh kadar air yang terkandung didalam produk. Semakin tinggi kadar air maka semakin rendah densitasnya, begitu juga sebaliknya semakin rendah kadar air maka densitas juga akan meningkat [20].

\section{Pengaruh Adsorpsi Terhadap Kemurnian Gliserol}

Pada gambar 2 dapat dilihat secara umum kadar gliserol akan meningkat seiring dengan bertambahnya persen adsorben $(\% \mathrm{w} / \mathrm{w})$. Kadar gliserol tertinggi diperoleh pada gliserol : $\mathrm{H}_{3} \mathrm{PO}_{4}$ $(\mathrm{n} / \mathrm{n})$ 1:0,6 dengan persen adsorben $15 \%$ sebesar $67,222 \%$ sedangkan kadar gliserol terendah diperoleh pada gliserol : $\mathrm{H}_{3} \mathrm{PO}_{4}(\mathrm{n} / \mathrm{n})$ 1:0,2 dengan persen adsorben $3 \%$ sebesar $40,998 \%$. Semakin bertambahnya kosentrasi adsorben, maka semakin banyak molekul adsorbat dan adsorben yang saling berinteraksi dalam proses adsorpsi. Pengotor seperti asam lemak bebas, metil ester, air dan kalium semakin banyak yang teradsorpsi [3]. Aziz (2014) dalam penelitiannya melaporkan bahwa persen konsentrasi zeolit sebesar $12 \%$ dari massa sampel adalah yang terbaik untuk penambahan adsorben dengan kadar gliserol mencapai $88,91 \%$ [3]. Lestari (2015) dalam penelitiannya melaporkan bahwa pada penambahan berat semen putih yang terbaik adalah sebanyak 5 gram dengan kemurnian gliserol yang diperoleh adalah $84,20 \%$. Semakin banyak semen putih yang ditambahkan maka kadar gliserol yang di peroleh semakin meningkat. Sedangkan semen putih dalam jumlah sedikit akan mengakibatkan proses penyerapan warna tidak berjalan optimal [12].

Mardhiyah (2013) dalam penelitiannya melaporkan bahwa penambahan adsorben fly ash yang terbaik adalah 10 gram dengan kemurnian gliserol $89,02 \%$. Semakin banyak penambahan massa fly ash maka semakin banyak pula impurities (adsorbat) yang dapat diadsorpsi oleh fly ash. Hal ini berkaitan dengan semakin banyaknya media untuk adsorbat terdifusi ke permukaan adsorben. Selain itu fly ash juga mampu mengadsorpsi zat warna sehingga 
gliserol yang awalnya berwarna kuning-gelap menjadi kuning-bening [15].

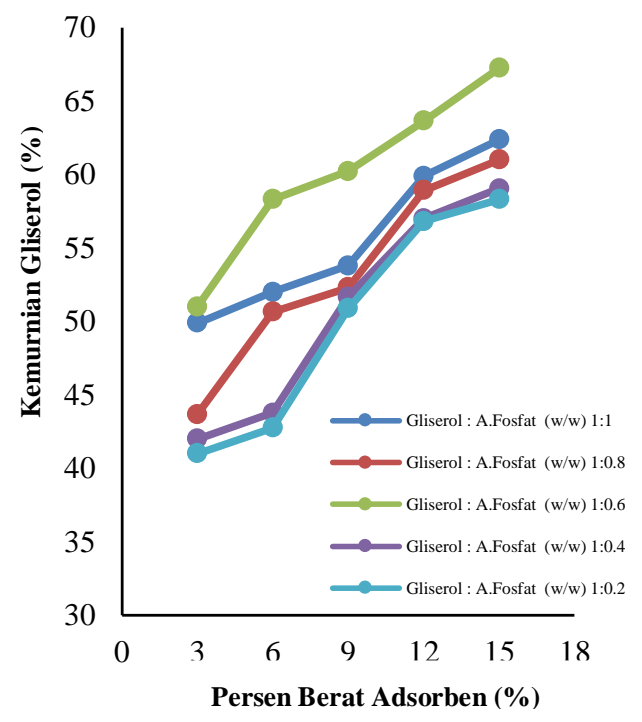

Gambar 2. Hubungan Persen Berat Adsorben (\% w/w) Terhadap Kemurnian Gliserol.

\section{Karateristik Gliserol Murni}

Tabel 3. Sifat Fisika Crude Gliserol, Gliserol Hasil Pemurnian, dan Gliserol Standard.

\begin{tabular}{|l|l|l|l|}
\hline $\begin{array}{l}\text { Sifat } \\
\text { Fisika }\end{array}$ & $\begin{array}{l}\text { Gliserol } \\
\text { Hasil } \\
\text { Asidifikasi }\end{array}$ & $\begin{array}{l}\text { Gliserol } \\
\text { Hasil } \\
\text { Adsorpsi }\end{array}$ & $\begin{array}{l}\text { Gliserol } \\
\text { Standard } \\
\text { BS 2621 } \\
\mathbf{1 9 7 9}[\mathbf{1}]\end{array}$ \\
\hline $\begin{array}{l}\text { Kadar } \\
\text { Gliserol } \\
(\%)\end{array}$ & 58,135 & 67,222 & $>80$ \\
\hline $\begin{array}{l}\text { Densitas } \\
\left(\mathrm{g} / \mathrm{cm}^{3}\right)\end{array}$ & 1,156 & 1,1710 & 1,2671 \\
\hline $\begin{array}{l}\text { Kadar abu } \\
(\%)\end{array}$ & 16,096 & 13,852 & $<10$ \\
\hline $\begin{array}{l}\text { Kadar air } \\
(\%)\end{array}$ & 3,784 & 2,796 & $<10$ \\
\hline $\begin{array}{l}\text { MONG } \\
(\%)\end{array}$ & 21,985 & 16,130 & $<2,5$ \\
\hline Warna & Coklat Gelap & Bening & Bening \\
\hline
\end{tabular}

Pada tabel 3 dapat dilihat perbandingan antara karakteristik gliserol hasil asidifikasi dan gliserol hasil adsorpsi, serta standard gliserol yang ditetapkan berdasarkan British Standard 2621 : 1979. Dapat dilihat pada tabel 3, gliserol hasil pemurnian dalam penelitian ini belum sesuai dengan gliserol standard BS 2621 : 1979. Hal ini disebakan karena kadar abu, kadar air dan MONG yang terlalu tinggi yang terkandung pada gliserol tersebut. Penurunan kadar air disebabkan karena sebagian air teradsorpsi oleh adsorben.
Dimana kadar air makin rendah maka densitasnya akan makin tinggi. Menurunnya kadar abu disebabkan menurunnya $\mathrm{pH}$. Hal ini disebakan karenakan semakin rendah $\mathrm{pH}$ maka semakin baik proses penguraian sabun menjadi asam lemak sehingga sisa-sisa logampun akan lebih rendah [20].

\section{Kesimpulan}

Hasil kemurnian tertinggi yang dihasilkan pada penelitian ini adalah $67,222 \%$ yang diperoleh pada rasio berat gliserol : asam fosfat (w/w) 1:0,6 dengan persen berat adsorben $15 \%$. Hasil analisa gliserol yang sudah dimurnikan baik densitas, kadar air, kadar abu , kadar gliserol dan juga MONG belum memenuhi standard gliserol komersial berdasarkan British Standard 2621:1979.

\section{Daftar Pustaka}

[1] M. S. Ardi, M. K. Aroua, N. A. Hashim, Progress, Prospect and Challenges in Glycerol Purifcation Process, Renewable and Sustainable Energy Reviews, 42 (2015) 1164-1173.

[2] A.Isalmi, S. Nurbayti, F. Luthfiana, Pemurnian Gliserol dari Hasil Samping Pembuatan Biodiesel Menggunakan Bahan Baku Minyak Goreng Bekas, UIN Syarif Hidayatullah, Jakarta, 2008.

[3] A. Isalmi, T. Las, A. Shabrina, Pemurnian Crude Glycerol dengan Cara Pengasaman dan Adsorpsi Menggunakan Zeolit Alam Lampung, Chem. Prog, Vol. 7, No. 2, November 2014.

[4] C. Elisa, D. Oroa, M. Bonatob, V. Oliveirac, M.V. Tresd , M. L. Mignonia, R. M. Dallagoa, A new approach for salts removal from crude glycerin coming from industrial biodiesel production unit, Journal of Environmental Chemical Engineering, 7 (2019) 102883.

[5] C. Jiaxin, S. Yan, X. Zhang, R. D. Tyagi , R. S. Valero, Chemical and Biological Conversion of Crude Glycerol Derived from Waste Cooking Oil to Biodiesel, Waste Management, xxx (2017) xxx-xxx.

[6] C.G. Chol, R. Dhabhai, A.K. Dalaia, M. Reaney, Purification Of Crude Glycerol Derived From Biodiesel Production Process: Experimental Studies And Techno-Economic Analyses, Fuel Processing Technology, 178 (2018) 78-87.

[7] D. Ravi, E. Ahmadifeijani, A. Dalai, M. Reaney, Purification of Crude Glycerol Using a Sequential Physico-Chemical Treatment, Membrane Filtration, and Activated Charcoal Adsorption, Separation 
and Purification Technology, 168 (2016) 101-106.

[8] H. Aleksander, P. Kosmela, K. Formela, L. Piszczyk, J.Haponiuk, Potential Applications Of Crude Glycerolin Polymertechnology Current State And Perspectives, Renewable and Sustainable Energy Reviews, 66 (2016) 449-475.

[9] I. H. Ernawati, R. Sitorus, N. Mulianingtias, F. Welan. 2016, Efektivitas Adsorpsi Logam $\mathrm{Pb}^{2+}$ dan $\mathrm{Cd}^{2+}$ Menggunakan Media Adsorben Cangkang Telur Ayam, Jurnal Konversi, 5(1) 1-7.

[10] J.Krisnawati, Pembuatan dan Karakterisasi Adsorben Cangkang Telur Bebek yang Diaktivasi Secara Termal, Skripsi, Universitas Sumatera Utara, Medan, 2013.

[11] Katada, katadata.co.id, 2018, Diakses pada tanggal 1 Desember 2018.

[12] Lestari, W. Suirta, Pengaruh Konsentrasi Asam Fosfat dan Berat Semen Putih Sebagai Adsorben dalam Pemurnian Crude Gliserol, Jurnal Kimia, 9(2) (2015) 279-288.

[13] Luo, Xialon, Xumeng, S.Cui, Y. Li, ValueAdded Processing Of Crude Glycerol Into Chemicals And Polymers, Bioresource Technology, 215 (2016) 144-154.

[14] M. Mamay, A. Taufiq, P. W. Subagja, Pemanfaatan Limbah Cangkang Telur Sebagai Biosorben Untuk Adsorpsi Logam $\mathrm{Pb}$ dan Cd,Jurnal Sains Natural Universitas Nusa Bangsa, 5(1) (2015) 92-100.

[15] N. Mardhiyah, Peningkatan Kadar Gliserol Hasil Samping Pembuatan Biodiesel dengan Metode Adsorpsi Asam Lemak Bebas (ALB) Menggunakan Fly Ash, Jurnal Konversi 2(2013).

[16] Nanda, Yuan, Qin, Poirier dan Chunbao, Purification of Crude Glycerol using Acidification: Effects of Acid Types and Product Characterization. Department of Chemical and Biochemical Engineering, Research Article Austin Chemical Engineering, Western University, London, 2014.

[17] Nasir, Mirus and M. Ismail, Purification Of Crude Glycerol From Transesterification Reaction Of Palm Oil Using Direct Method And Multistep Method, IOP Conference Series: Materials Science and Engineering, 2017.

[18] Pan, Chaozhi, G. A. Tan, L. Ge, C. L. Chen, J. Y. Wang, Two-Stage Microbial Conversion Of Crude Glycerol To 1,3Propanediol And Polyhydroxyalkanoates After Pretreatment, Journal of Environmental Management, 232 (2019) 615-624.
[19] M. Pettinato, S. Chakraborty, H. Arafat, http://dx.doi.org/10.1016/j.ecoenv.2015.05 .046i, 2015, Diakses pada tanggal 1 Desember 2018.

[20] R. Ulfa, Pengaruh Jenis Asam dan pH Pada Pemurnian Residu Gliserol Dari Hasil Samping Produksi Biodiesel, Skripsi, Universitas Sumatera Utara, Medan, 2006.

[21] T. Meisam, K. Karimi, I. Sarvari, R. Kumar. Recent Trends In Biodiesel Production, Biofuel Research Journal, 7 (2015) 258-267.

[22] H. W. Tan, A. R. A. Aziz dan M. K. Aroua, Glycerol Production And It's Applications As A Raw Material: A Review, Renewable and Sustainable Energy Reviews, 27 (2013) 118-127

[23] Thammarat, Design and Economic Analysis Of 1, 2 - Propanediol Derived From Crude Glycerol, The Petroleum and Petrochemical College, Chulalongkorn University, Bangkok Thailand, 2016.

[24] W. M. Surbakti, Pemurnian Gliserol dengan Metode Asidifikasi Asam Klorida dan Ekstraksi dengan Pelarut Kloroform, Skripsi, Departemen Teknik Kimia, Universitas Sumatera Utara, Medan, 2016. 